\title{
Migration and health in China: Linking sending and host societies
}

\author{
Senhu Wang \\ sw768@cam.ac.uk \\ Department of Sociology, University of Cambridge \\ 16 Mill Road, Cambridge, United Kingdom, CB2 1SB
}

Yang Hu
yang.hu@lancaster.ac.uk
Department of Sociology, Lancaster University
Bowland North, Bailrigg, Lancaster, United Kingdom, LA1 4YN.

\begin{abstract}
China's large-scale internal migration has stimulated ongoing debates about consequences of geographical mobility for population health. While existing research predominantly focused on migrants' health in host societies, the complex relationship between migration and health throughout the full migratory cycle remains understudied. Analyzing data from 2010 China General Social Survey $(N=1,660)$, we investigate variations in migrants' physical and mental health across four distinct migratory stages - intended, temporary, permanent and return migration. Supporting the "healthy migrant" and "salmon" hypotheses, we found that intended migrants have better health than rural residents with no migration intention, and migrants have better health than return migrants. The health disparity between non-migrants and migrants is largely explained by selective demographic and socioeconomic traits, but not health behaviors. Rural-to-urban migration is associated with adverse health outcomes, particularly among permanent migrants. The findings suggest potential health risks associated with rural-to-urban migration and migrant assimilation in urban China.
\end{abstract}

Keywords: China; hukou; health; health behavior; migration; socioeconomic status. 


\section{Introduction}

China's socioeconomic and cultural transformations have led to rapid yet uneven urbanization, which has helped motivate large-scale rural-to-urban migration. In 2016, 245 million Chinese, most of whom were from rural areas, resided in a place other than their hukou (household) registration, accounting for around 17\% of the country's population - the largest non-wartime migration ever in human history (National Population and Family Planning Committee, 2017). The phenomenal migration, coupled with China's distinctive institutional and healthcare settings, have important implications for population health (X. Hu, Cook, \& Salazar, 2008; Mou, Griffiths, Fong, \& Dawes, 2013).

Key to our understanding of population health in a migration context, the "healthy migrant paradox" describes the observation that new migrants are healthier than their host society counterparts, but their health advantage diminishes as they integrate into the host society (Thomson, Nuru-Jeter, Richardson, Raza, \& Minkler, 2013; Vang, Sigouin, Flenon, \& Gagnon, 2017). Although the paradox was derived from the comparison between migrants and native populations in host society (Vang et al., 2017), its explanatory mechanism is largely predicated on assumptions of selective migration both into and out of host society (Thomson et al., 2013). As the assumptions were largely assumed rather than empircially assessed, potential mechanisms underlying the empirical observations in China and other countries that migrants are healthier than host society natives remain unclear (J. Li \& Rose, 2017; Thomson et al., 2013; Vang et al., 2017).

In China, existing studies have predominantly focused on how rural migrants' health is shaped by their experiences in urban destinations (Chen, 2011; J. Li \& Rose, 2017). Only 
sparse attention has been paid to pre-migration experiences in sending societies; and the health status of return migrants also remains understudied (Lu \& Qin, 2014; Piotrowski \& Tong, 2013). However, the existence of endogenous selection that healthy people are more likely to migrate and unhealthy migrants are more likely to return home underlines the complex inter-linkages between migratory behavior and health outcomes at distinct migratory stages (Chen, 2011; Lu \& Qin, 2014). Thus, without considering both sending and host societies, competing theoretical conjectures and mechanisms in terms of migrant selectivity (e.g., selective out- and return migration) and migration experience (e.g., integration into or segregation from host societies) remain jumbled in explaining health disparities between migrants and non-migrants. The need to systematically disentangle these mechanisms underlying the relationship between migration and health remains a major challenge in existing research.

To address this limitation, we devise a new analytical framework to systematically explore the health status of internal migrants in China. Notably, the framework connects sending and host societies by distinguishing distinctive migratory stages and by providing a holistic view of how migrants' health varies across multiple stages throughout the full cycle of migration between rural and urban China. Furthermore, since health is a multidimensional construct, we go beyond the generalized notion of "migrant health" (Lu \& Qin, 2014) to provide a more nuanced and multifaceted understanding of migrants' health profiles by comparatively assessing physical and mental health outcomes.

\section{Theoretical Framework}


China's internal migration is characterized by circular population mobility between rural and urban areas (Lu \& Qin, 2014). Thanks to the country's rapid development in public transportation networks, rural Chinese could not only migrate to urban areas at relatively low costs, those who have migrated to urban areas could also readily access and remain connected with their sending places. For example, many rural migrants are seen to return home periodically to celebrate important festivals, help with agricultural work during busy farming seasons, and visit their family members and friends (Liang, 2016). The bidirectional, temporary and circular nature of China's internal migration means that the relationship between migration and health may be complex and can only be understood through a perspective that covers the whole migratory process from sending to host societies and from host societies back to sending places.

To disentangle the complex relationship between migration and health, we devise a new analytical framework, which links sending and host societies by considering people's migration intentions as well as distinguishing distinct migratory stages (Y. Hu, 2016), as depicted in Figure 1. (1) Rural natives refer to rural residents who have never migrated and do not intend to migrate to urban areas. (2) Intended migration refers to a stage in which rural residents intend to migrate to urban areas. (3) Temporary migration refers to a stage in which rural residents have migrated to urban areas but have not obtained an urban hukou to enable urban settlement. (4) Permanent migration refers to the settlement of rural residents in urban areas after having obtained an urban hukou. (5) Return migration refers to the movement of rural migrants back to rural areas. The framework captures the full cycle of China's internal migration between rural and urban areas, thus enabling us to examine health disparities 
between migrants and non-migrants and among migrants at distinct migratory stages before, during and after geographical mobility.

\section{[Insert Figure 1 Here]}

While the framework presents an ideal typology of distinct migratory stages, it should be noted that actual migration may not necessarily take place in a linear fashion as depicted in Figure 1. For example, previous research showed that some people may forgo their migration intention and there is also considerable heterogeneity in the timeframe within which people act upon their intention (Clark \& Lisowski, 2017; Coulter, 2013; Kley, 2011). Moreover, some temporary migrants may never obtain an urban hukou and are caught in long-term, repetitive circular mobility between rural and urban areas (Liang, 2016). These examples indicate that real-life migratory behaviors can be fuzzy and messy and are often characterized by senses of ambivalence and ambiguity. Nonetheless, our framework marks a useful starting point to go beyond the dichotomy between sending and host societies to explore the role of health in shaping migratory behavior as well as the health impact of migration.

\subsection{Migrant selectivity: "Healthy migrant" and "salmon" hypotheses}

It is widely acknowledged that migration is a selective process (Chen, 2011). In China, migrant selectivity often involves selection into and out of the internal circular migratory flow (X. Hu et al., 2008). Health is key to the selection process because it plays a pivotal role in determining whether and when people tend to migrate, and whether and when they may return home (Chen, 2011). In terms of out-migration, the "healthy migrant" hypothesis postulates a positive selection process (Lu \& Qin, 2014): because migration represents a 
demanding journey that often entails separation from family members, disruption of social ties, and adaption to a new environment, people who are selected into migration tend to be healthier than their non-migrant counterparts (Chen, 2011; Thomson et al., 2013; Tong \& Piotrowski, 2012). In China, as a large number of rural residents migrate to urban areas to undertake physically demanding jobs (Liang, 2016), physical rather than mental health may be particularly relevant to the selection into rural-to-urban migration.

In terms of return migration, the "salmon" hypothesis posits that compared with healthy migrants, unhealthy migrants are more likely to be eliminated from the migratory cycle to return home (Lu \& Qin, 2014; Thomson et al., 2013; Wallace \& Kulu, 2018). While many rural Chinese migrate to urban areas to work as manual laborers (Liang, 2016), migrants who encounter health problems not only experience decreased productivity and earnings, they are also challenged by costly healthcare due to a lack of access to urban welfare (Lu \& Qin, 2014; Xie, Wang, Chen, \& Ritakallio, 2017). This, alongside a lack of family support, may motivate less healthy migrants to return to rural areas. Because physical health problems may directly undermine migrants' capability to perform manual labor while mental health may only do so indirectly, it is reasonable to expect that impaired physical health may be more likely than poor mental health to motivate return migration.

Identifying the existence and extent of selective out-migration and return migration is crucial as the "export" of healthy population from rural peripheries to urban centers (i.e., the "healthy migrant" hypothesis) and the "elimination" of less healthy rural migrants from urban back to rural areas (i.e., the "salmon" hypothesis) may exacerbate China' rural-urban health inequalities (X. Hu et al., 2008; L. Wang \& Zhou, 2016). However, only a few studies have 
focused on the selective nature of China's internal migration and its implications for population health, yielding mixed findings (Chen, 2011; Lu and Qin, 2014; Xie et al., 2017; Tong and Piotrowski 2012). While Lu and Qin (2014) and Chen (2011) found that rural residents with better self-rated health are more likely to migrate, Tong and Piotrowski (2012) did not find statistically significant evidence in support of selective out-migration.

The inconsistent findings may in part arise from the lack of attention to the migratory cycle as a whole and pre-migration processes in sending societies in particular. Prior research has often compared those who migrated and those who stayed in sending places (J. Li \& Rose, 2017; L. Zhang, Liu, Zhang, \& Wu, 2015). The two are incomparable not only because the process of self-selection takes the form of social expectation before actual migratory behavior materializes (Y. Hu, 2016), but also because migration behavior is a poor proxy of self-selection, as rural-to-urban mobility represents a mixed pool of voluntary and forced migrants who move to urban areas due to reasons such as land confiscation (Xiao \& Zhao, 2018). This means that we need to prospectively explore people's migration intentions in rural sending societies before migration takes place to fully disentangle the process of self-selection. If healthy people indeed self-select into migration, we would expect Hypothesis 1A to hold. Hypothesis 1B specifies the "salmon" thesis that unhealthy people are selected out of the migration cycle.

H1A (healthy migrant selection): Rural residents who intend to migrate to urban areas are healthier than their counterparts who do not intend to migrate, and the difference is greater for physical than for mental health.

H1B ("salmon" selection): Return migrants are less healthy than their counterparts who 
remain in the cycle of rural-to-urban migration, and the difference is greater in physical than mental health.

\subsection{Migration and health}

Migration may entail diverse health consequences (J. Li \& Rose, 2017). In a negative light, migration may undermine both the physical and mental health of migrants. As rural migrants tend to congregate in deprived urban neighborhoods (Y. Hu \& Coulter, 2017) and undertake physically demanding jobs featuring long working hours and low wages (Liang, 2016), the exposure to poor living and working conditions could potentially impair migrants' physical health. Migration also entails disruption of social connections, and the resultant sense of loneliness, combined with heightened stress of living within resource constraints in urban areas, may undermine migrants' emotional and mental well-being (Y. Hu \& Coulter, 2017; J. Li \& Rose, 2017). Meanwhile, the sociocultural discrimination faced by migrants in host societies could add to their mental stress (Xie et al., 2017). Furthermore, the psychological dissonance between high expectations of urban lives and realities of social marginalization and segregation could generate acculturative stress (J. Zhang, Li, Xiaoyi, Ae, \& Xiong, 2009). The negative health impact of migration has been documented in several regional studies in China, which showed that it was more likely for migrants in Beijing, Hangzhou and southwestern China to suffer from physical or mental health problems than their rural non-migrant counterparts (L. Li et al., 2007; X. Li et al., 2009; Yang, 2014).

By contrast, a different line of studies suggest that migration may entail health benefits (Hesketh, Ye, Li, \& Wang, 2008; L. Zhang et al., 2015). Due to considerable disparities 
between rural and urban China in living standards, healthcare and welfare provision (Liang, 2016), rural migrants living in developed urban areas may have the opportunity to access more abundant socioeconomic resources and health facilities and services, compared to their rural non-migrant counterparts (Mou et al., 2009). The relatively high standard of living in urban areas could potentially benefit migrants' physical health, although such benefits may be limited by the social and institutional segregation of rural migrants. Moreover, urban residence might also benefit migrants' mental health by bolstering their life aspirations and conferring them with senses of "freedom" and "self-actualization" (L. Li et al., 2007). Comparing rural-to-urban migrants and non-migrant rural residents, a few recent studies seem to lend support to the positive implications of migration for both physical and mental health (Dai et al., 2015; Hesketh et al., 2008; L. Zhang et al., 2015).

However, these observations may be an artifact arising from the "healthy migrant" and “salmon" selections (Lu \& Qin, 2014). The comparison between migrants and an amalgamated category of rural residents is problematic because the rural population is formed of diverse sub-groups. Return migrants are likely to have been eliminated from the migratory cycle due to poor health. The low propensity for rural migrants with no intention to migrate renders them an inappropriate control group in assessing the impact of migration (Heckman, Ichimura, \& Todd, 1998). Instead of treating rural residents as a whole, we propose to single out rural residents who intend to migrate but have not yet migrated to urban areas and have no previous migratory experience as the control group, i.e., excluding rural residents with no migration intention as well as return migrants from the comparison, in assessing the two competing hypotheses below: 
H2A (detrimental impact of migration): Rural-to-urban migrants are less healthy than rural intended migrants, in both physical and mental health.

H2B (beneficial impact of migration): Rural-to-urban migrants are healthier than rural intended migrants, in both physical and mental health.

\subsection{Hukou status and the health consequence of migration}

Our hypotheses on both detrimental and beneficial health consequences of migration are predicated on the degree to which migrants are segregated from or integrated into host societies. In China, the hukou system plays a pivotal role in demarcating the socioeconomic, cultural and symbolic boundaries between temporary rural migrants, permanent migrants and urban natives (Liang, 2016). The hukou system was established in the 1950s to restrict population mobility between rural and urban areas by assigning each Chinese citizen a place of residence registration (Chan, 2010). The initial goal of the system was to ensure the provision of sufficient labor force in the agricultural and industrial sectors of production. Due to the rapid pace of urbanization and the rise of socioeconomic disparities between rural and urban China following the 1978 economic reform and open-door policy, urban hukou holders are afforded access to more abundant socioeconomic and health resources and have higher symbolic status than their rural counterparts (Chan, 2010; X. Hu et al., 2008).

An urban hukou differentiates permanent rural migrants from their temporary counterparts by enabling the former to exit the migratory cycle to permanently settle down in urban areas and to access urban institutions and resources (Y. Hu, 2016). Without urban hukou, temporary migrants are not only subject to marginalization in the urban labor market, 
but also have limited access to public and health resources such as social insurance and medical subsidy (Liang, 2016; Mou et al., 2009). In China, three healthcare packages are assigned to different population groups based on their hukou and employment status (G. Liu, Vortherms, \& Hong, 2017; S. Wang, 2018). The Urban Employee Basic Medical Insurance (UEBMI) launched in 1998 was the first national system in China providing healthcare for urban hukou holders formally employed in urban sectors. The New Rural Cooperative Medical System (NRCMS) was then introduced in 2003 to cover the healthcare of all rural hukou holders. Finally, the Urban Resident Basic Medical Insurance (URBMI) was introduced in 2007 for urban hukou holders who were otherwise uncovered by the UEBMI. Although the three packages are designed to provide universal healthcare coverage for all Chinese citizens, temporary rural migrants residing in urban areas are particularly disadvantaged in their ability to access health services, compared to their urban counterparts (G. Liu et al., 2017). This is primarily due to a more limited range of health services and lower reimbursement rate covered by the NRCMS as opposed to the UEBMI and the URBMI (G. Liu et al., 2017). Moreover, the inflexibility of NRCMS, which fixates rural hukou holders' access to health welfare to their rural places of registration, also inhibits rural-to-urban migrants from accessing adequate healthcare in urban areas (G. Liu et al., 2017).

Given the importance of hukou in conferring healthcare services and resources, comparing temporary and permanent migrants promises a nuanced understanding of how population policies may mitigate or exacerbate health inequalities resulting from migration. If migration leads to detrimental health outcomes due to migrants' displacement from their 
sending places as well as a lack of access to health resources in host societies (Mou et al., 2009), we would expect permanent migrants to have a better state of health than their temporary counterparts. Alternatively, if migration entails health benefits by enabling access to social and health resources in host societies, we would expect permanent migrants to enjoy such benefits to a greater extent than their temporary counterparts. Additionally, as temporary migrants may be prevented by a lack of access to healthcare from staying in urban areas, differentiated hukou status may constitute an underlying explanation for the "salmon" selection of unhealthy temporary (as opposed to permanent) migrants out of the migratory cycle back to rural areas.

H3 (hukou difference): Compared with temporary migrants, permanent migrants enjoy a higher level of physical and mental health.

\section{Method}

\subsection{Data and sample}

The data analyzed in this research are from the 2010 China General Social Survey (CGSS). Using a multi-stage stratified probability-proportional-to-size random sampling approach, the sample is representative of the adult population aged 18 and above in China, with an overall response rate of $74.3 \%$. Ideal for the current study, the 2010 CGSS provides up-to-date and nationally representative information on respondents' health status, migration intention and behavior. Notably, as the CGSS sampling procedure was based on respondents' location of residence rather than location of hukou registration, the sample is representative of China's rural-to-urban migrants who are a highly mobile group of people, often residing in 
temporary and unregistered urban locations such as construction sites and factory dormitories.

To construct our analytical sample, we first limited our focus to respondents aged between $18-55$ years old who are in their prime working age and are unlikely to have stayed in rural areas or migrated to urban areas for health-related reasons $(n=8,259[11,783-$ $3,524])$. Second, health measures were only included in a self-completion module completed by a representative subsample of the original CGSS sample, which further limited the size of our analytical sample $(n=2,732[8,259-5,527])$. Third, as we focus on the health impact of migration, we excluded urban natives who were born with an urban hukou and live in urban areas $(n=1,955[2,732-777])$, and 11 urban natives who migrated to rural areas $(n=1,944$ $[1,955$ - 11]). Lastly, we eliminated rural respondents who did not report clear migration intention $(n=1,824[1,944-120])$ as well as intended migrants who had previously migrated $(n=1,679[1,824-145])$. After dropping 19 cases with missing information, the final analytical sample contains 1,660 respondents providing valid information on all key variables. Further tests showed that the 19 missing cases were not statistically skewed in key sociodemographic features.

\subsection{Method and variables}

As sociodemographic traits of individuals may vary considerably across different migratory stages, it is key to take account of the confounding characteristics when examining the relationship between migration and health. To this end, we used the method of propensity score matching (PSM). In the PSM procedure (see Guo and Fraser [2010] for more 
information), we first estimated the probability of receiving treatment (e.g., migration), and then compared outcome variables between control (e.g., intended migrants) and treated groups (e.g., migrants) provided that they had a similar probability of receiving the treatment (e.g., migration behavior). Compared with regression-based methods, PSM saves degrees of freedom and provides a more efficient means to ensure the comparability between control and treatment groups, particularly with small samples (Guo \& Fraser, 2010; Heckman et al., 1998).

\subsubsection{Health outcomes}

To measure respondents' health, we used the 12-Item Short Form Health Survey (SF-12), which has been widely used as a reliable instrument to measure health outcomes (Ware, Kosinski, \& Keller, 1998). The SF-12 contains eight indicators formed of 12 items: physical functioning (2 items), role limitations due to physical health problems (2 items), bodily pain $(1$ item $)$, general health $(1$ item $)$, vitality $(1$ item $)$, social functioning $(1$ item $)$, role limitations due to emotional problems ( 2 items), and mental health (2 items) (see Ware et al. [1998] for more information). The first six items primarily measure physical health, and the latter six items measure mental health. Following Ware et al. (1998), we calculated two weighted composite scores to measure physical and mental health, respectively-namely the Physical Component Summary (PCS, $M=55.67, S D=8.79, \alpha=0.87$ ) and Mental Component Summary (MCS, $M=44.50, S D=10.24, \alpha=0.83$ ). For both indexes, a higher score indicates a better state of self-reported health. 


\subsubsection{Treatment variables}

As depicted in Figure 1 and also detailed in our theoretical discussion, we divided the sample into five sub-groups, based on the respondents' location of residence (rural vs. urban), hukou status (rural vs. urban), migration experience (ever migrated vs. never migrated) and migration intention (whether one intends to migrate to an urban area in five years' time).

We combined each two out of the five groups and distinguish between the control (0) and treatment (1) groups to test each set of hypotheses. First, we compared rural natives (0) and intended migrants (1) to test the "healthy migrant" hypothesis. Second, we compared migrants $(0$, temporary and permanent migrants combined) and return migrants (1) to test the "salmon" hypothesis. Third, we compared intended migrants $(0)$ and migrants $(1$, temporary and permanent migrants combined) to estimate the health impact of migration. Fourth, to estimate the differentiated health impact of migration by hukou status, we conducted three sets of comparisons: intended migrants (0) vs. temporary migrants (1); intended migrants (0) vs. permanent migrants (1); and temporary migrants (0) vs. permanent migrants (1).

\subsubsection{Matching covariates}

In the PSM procedure, we took account of a wide range of covariates that are related to individuals' health status and migration behavior (Chen, 2011; Tong \& Piotrowski, 2012). We included respondents' age $(M=39.19, S D=9.67)$, its squared term, and gender $(54.6 \%$ women). We also included a dummy variable measuring the respondents' partnership status distinguishing between partnered respondents (married and cohabiting, 86.0\%) and singletons (never married, divorced and widowed, 14.0\%). We also distinguished respondents who had 
no child (19.6\%), pre-school children (age 0-5: 13.7\%), school age children (age 6-17: $34.9 \%$ ), and adult children (age 18 and above: 31.7\%), respectively. Because regional disparities in China's economic development has been a major driver of population mobility, we further controlled for the logged value of average income measured in the unit of Chinese yuan in the respondents' current provinces of residence $(M=9.44, S D=0.23)$. Unfortunately, the high rate of missing data prevented us from controlling for the duration of migration. However, previous research using data from the 2006 CGSS showed that the duration of migration closely correlates with age (Y. Hu, 2016).

\subsubsection{Post-matching mediators}

It is possible that the health impact of migration may be partly explained by variation in health behaviors. Thus, we included three mediating dummy variables to capture whether the respondents were regular smokers $(31.1 \%)$, regular alcohol consumers $(38.4 \%)$, and whether they participated in regular physical exercise (i.e., for 20 minutes and longer per day; $40.1 \%$ ), respectively, in the year prior to the survey. Since hukou difference in the health impact of migration may also be explained by individuals' socioeconomic status (SES), we also included the measures for one's education and occupational status as mediating covariates. Respondents' highest educational qualification was captured using five categories: no education (9.5\%), primary school (24.6\%), middle school (36.9\%), high school $(10.8 \%)$, and college/university and above (18.3\%). Occupational status was measured using the Erikson-Goldthorpe-Portocarero (EGP) classification: no work (36.5\%), higher controller (EGP I, II \& V: 20.6\%), routine non-manual (EGP IIIa, IIIb, IVa \& IVb: 9.4\%), manual (EGP 
VI, VIIa: 27.5\%), and farm-related and other work (EGP IVc \& VIIb: 6.0\%). The health behavior and SES mediators were not included as matching covariates, but in regression adjustments after PSM. Because people often migrate for the purpose of education or work and health behaviors may change throughout the migratory process, their inclusion in PSM could contaminate the matching procedure (Guo \& Fraser, 2010).

\subsection{Analytic procedures}

In the PSM procedure, we first fitted a series of binomial logistic regression models with all matching covariates (not including mediators) to predict the probability of receiving treatment for each set of comparison. Next, local linear regression method with replacements and ties was used to match control and treated groups. The matching procedure was limited to the region of common support, i.e., where a given case has a positive probability of being both treated and untreated (Guo and Fraser, 2010). Local linear regression matching was used due to its efficiency; and other methods such as nearest neighbor, radius and caliper matching were used for robustness checks, which yielded similar results. Finally, the average treatment effects on the treated (ATT) were estimated according to the following equation:

$$
\mathrm{ATT}=\mathrm{E}\left(\mathrm{Y}_{\mathrm{i}}^{\mathrm{T}} \mid \mathrm{D}_{\mathrm{i}}=1\right)-\mathrm{E}\left(\mathrm{Y}_{\mathrm{i}}^{\mathrm{C}} \mid \mathrm{D}_{\mathrm{i}}=1\right)
$$

where $\mathrm{Y}$ denotes outcome variables, $\mathrm{T}$ denotes the treated group, $\mathrm{C}$ denotes the control group, $i$ denotes each respondent's unique identifier, $\mathrm{D}=1$ denotes the receipt of treatment, $\mathrm{E}$ denotes expected outcome values for the counterfactual scenario (Guo \& Fraser, 2010). We report both raw differences and matched ATTs for all comparisons. Further to the PSM procedure, we conducted ordinary least squares regression adjustments (RA) to the matched 
samples by including the mediators - health behavior and SES measures - to examine the extent to which these measures mediated any health disparities across distinct migratory stages.

\section{Results}

\subsection{Descriptive statistics}

Table 1 reports the descriptive statistics by different migratory stages. The $F$ statistics indicate significant health disparities between the five groups $(p<.001)$. Specifically, intended, temporary and permanent migrants had better physical and mental health than rural natives and return migrants. Moreover, the respondents' sociodemographic characteristics also varied considerably across the migratory stages. Intended, temporary and permanent migrants tended to be younger than return migrants and rural natives; and the former were also less likely to have a partner and children. Compared with their female counterparts, rural males were more likely to intend to migrate as well as to return to rural areas, which are consistent with the findings from previous research (Y. Hu, 2016; Lu \& Qin, 2014). In addition, migrants tended to reside in provinces with higher wage levels than non-migrants, which is not surprising as regional wage disparity is a major driver of China's rural-to-urban migration (Liang, 2016).

\section{[Insert Table 1 Here]}

In terms of health behaviors, intended and return migrants were more likely to be regular smokers than those from the other groups. The rate of regular alcohol consumption was higher among intended, return and permanent migrants than the other groups. Temporary 
and permanent migrants were more likely to participate in regular physical exercise than those from the other groups. Lastly, permanent migrants had the highest level of educational attainment and occupational status, followed by temporary migrants, return migrants, intended migrants and then rural natives, which concurs with the observation that education and work are the two primary goals of migration (Y. Hu, 2016).

\subsection{Propensity score matching results}

Table 2 presents the sample balancing properties before and after PSM. The results show that the PSM procedure performed well in balancing the different sociodemographic traits between people at distinct migratory stages, because the inter-group differences in the matching covariates were not statistically significant at the $5 \%$ level for all comparisons after PSM.

[Insert Table 2 Here]

\subsubsection{The "healthy migrant" and "salmon" hypotheses}

Table 3 presents the average treatment effects on the treated (ATT) from the tests for the "healthy migrant" and "salmon" hypotheses. In Panel A, to test the "healthy migrant" hypothesis, we compared the health outcomes of rural natives and intended migrants. The results support the "healthy migrant" hypothesis (H1A) as well as our expected difference between physical and mental health. The raw differences show that intended migrants reported significantly better mental and particularly physical health than rural natives $(p$ $<.001)$. After adjusting for various sociodemographic traits using PSM, however, the 
disparities in both physical and mental health between the two groups reduced substantially in size. With the inclusion of SES and health behavior mediators, the ATTs for both health outcomes reduced further in size and became statistically non-significant. The results therefore suggest that the better state of health reported by intended migrants relative to rural natives may be attributed to the selective demographic and socioeconomic characteristics of the former, such as young age, high educational attainment and occupational status.

[Insert Table 3 Here]

Panel B of Table 3 presents the ATTs from the comparison between migrants (both temporary and permanent combined) and return migrants to test the "salmon" hypothesis. The results are partly consistent with the "salmon" hypothesis (H1B). The raw differences in health outcomes between the two groups show that return migrants had worse physical ( $p$ $<.01)$ and mental health $(p<.10)$ than current migrants, and the health disparity was more pronounced in physical health than in mental health. Selective demographic traits were only partly responsible for explaining the observed health disparity between the two groups: compared with their migrant counterparts, return migrants had poorer mental and physical health even after adjusting for demographic traits in the PSM procedure. Nevertheless, after adjusting for SES and health behaviors, the ATTs of return migration reduced substantially in size for both health outcomes and became statistically non-significant. Therefore, the results suggest that both SES and health behaviors play important roles in explaining the health disadvantage of return migrants relative to migrants.

\subsubsection{The impact of migration on health}


Panel A of Table 4 presents the results of the health impact of rural-to-urban migration and how the impact differed by hukou status. The results are in line with Hypothesis $2 \mathrm{~A}$ instead of Hypothesis $2 \mathrm{~B}$ in suggesting the adverse rather than beneficial health impact of migration. Both before and after PSM, we did not find any statistically significant differences in physical and mental health between intended migrants and migrants, although the former reported a slightly better state of health. However, after taking account of educational attainment and occupational status, the regression adjustment results indicate that migrants had much worse physical $(p<.001)$ and mental health $(p<.001)$, compared with their intended migrant counterparts. In other words, if were not for their higher educational attainment and occupational status relative to intended migrants, migrants would have been in a much poorer state of health than intended migrants. Although many rural Chinese people migrate to urban areas for education or work and the resultant uplift in SES may entail health benefits (Chen, 2011), the results suggest that the negative health impact of migration itself may have offset such benefits.

[Insert Table 4 Here]

\subsubsection{Hukou status and the health impact of migration}

Panels B, C and D of Table 4 report the results on whether the health impact of migration differed by migrants' hukou status between temporary migrants and permanent migrants. In Panels B and C, the raw differences show that both temporary and permanent migrants had worse physical and mental health than intended migrants, although the differences were only statistically significant at the $10 \%$ level. After adjusting for the 
sociodemographic traits using PSM, the differences changed little in size. For the comparison between temporary and intended migrants (Panel B), the regression adjustments for SES and health behaviors slightly reduced the differences in both health outcomes between the two groups. This is not surprising in that temporary migrants are often prevented by their rural hukou status from integrating into urban institutions, and their SES and lifestyle may remain similar to those of intended migrants (Liang, 2016). By contrast, in Panel C of Table 4, the results show that after adjusting for SES and health behaviors, permanent migrants had much poorer physical $(p<.01)$ and mental health $(p<.001)$ than intended migrants.

The detrimental health impact of permanent migration is further supported by the results from Panel D of Table 4, in which we directly compared the health of temporary and permanent migrants. After taking account of different SES and health behaviors between the two, permanent migrants reported a considerably poorer state of physical $(p<.001)$ and mental health $(p<.05)$ than temporary migrants. Therefore, the results confirm that the health impact of migration differed by hukou status. However, contrary to our expectation (Hypothesis 3), urban hukou — which facilitates permanent migrants' integration into urban institutions - exacerbated rather than mitigated the adverse health impact of rural-to-urban migration. While an urban hukou (and its associated resources) may entail health benefits, such benefits many have been offset by permanent migrants' prolonged experiences of marginalization and precarity in the urban space as they went through the challenging and lengthy process of obtaining an urban hukou (Z. Zhang \& Treiman, 2013).

\section{Discussion and conclusions}


Against the backdrop of rapid yet uneven socioeconomic and urban development in China, millions of rural Chinese migrate to urban centers every year. While much research has focused on the socioeconomic consequences of China's rural-to-urban migration (Liang, 2016), the implications of this migration for population health has received relatively less attention (Mou et al., 2013). Most existing research has focused on how rural migrants' health is shaped by their experiences in host societies in urban China (Chen, 2011; J. Li \& Rose, 2017). However, scholars have paid scarce attention to pre-migration selection and return migration back to rural areas. Therefore, past studies are limited in their capability to account for endogenous migrant selectivity and to disentangle competing theories on the interrelation between geographical mobility and population health. To remedy the limitations of prior research, we have devised an analytical framework that takes account of both migration intention and return mobility to examine the ways in which Chinese people's physical and mental health vary across distinct migratory stages between sending and host societies.

First, this research uncovers the patterns of selection into and out of China's internal migration. Our findings provide new empirical evidence from a non-Western context in support of the "healthy migrant" and "salmon" hypotheses that were originally developed in the West (Thomson et al., 2013; Vang et al., 2017). Healthy rural Chinese were more likely to intend to migrate and thus self-select into rural-to-urban migration, and unhealthy rural migrants were more likely to return to rural areas. These health selection processes seem to be predicated primarily on physical rather than mental health. Through "exporting" healthy population from rural peripheries to urban centers and "eliminating" less healthy migrants back to rural areas, migrant health selection may exacerbate health inequalities between rural 
and urban China.

Our findings also provide nuanced insights into potential mechanisms underlying selective migration in terms of health in China. We found that different demographic characteristics (e.g., age, marital status, and presence of children) and SES (e.g., education and occupational status) largely mediated and thus explained the health advantage enjoyed by intended migrants over rural non-migrants as well as the poorer health reported by return migrants compared with current migrants. Nevertheless, health behaviors such as smoking, drinking and physical exercise was not associated with selective out-migration and return migration. Our findings lend support to previous research reporting a positive socioeconomic gradient of health (Y. Liu, Zhang, Liu, Li, \& Wu, 2018; Williams, Jephcote, Janta, \& Li, 2018), and they further imply that migrant health selection may operate in conjunction with processes of socioeconomic stratification in China.

Our results reveal the adverse health impact of China's rural-to-urban migration. Although a better living condition in urban areas was expected to benefit the health of rural-to-urban migrants, the migrants reported lower levels of physical and mental health compared with their counterparts who intended to migrate but were yet to do so, after taking account of socioeconomic status. This finding may not be surprising as rural migrants, particularly rural hukou holders who reside in urban areas on a temporary basis, are often subject to poor working condition, sociocultural discrimination and heightened stress arising from precarious living within resource constraints in urban areas (Chen, 2011; Liang, 2016; Yang, 2014). As a result, these adverse consequences of migration may have outweighed its potential positive impacts, thus undermining rural migrants' physical and mental health. 
Moreover, opposite to our hypothesis that urban hukou may enhance permanent migrants' health outcomes, permanent migrants reported lower levels of physical and mental health than their temporary counterparts. Although urban hukou enables permanent migrants to access abundant socioeconomic and health resources (Chan, 2010), the health benefits of such access may have been offset by the long-term margianlization and stress experienced by permanent migrants before they obtain an urban hukou. First, due to the demanding requirements and the long time it takes for one to obtain an urban hukou (Z. Zhang \& Treiman, 2013), lengthened exposure to marginalization and segregation may harm the health of permanent migrants to a greater extent than that of their temporary counterparts (Chen, 2011). Second, compared with temporary migrants, permanent migrants tend to have much higher expectations to achieve upward mobility and full integration into urban lives (Chen, 2011). The dissonance between their high expectations and actual experiences of social segregation could generate acculturative stress, which may undermine migrants' health (J. Zhang et al., 2009).

The hukou difference in Chinese migrants' health also adds to ongoing debates in Western countries on whether assimilation has a positive or a negative impact on migrants' health (S. Wang \& Mak, 2018). On the one hand, classical and revised straight-line assimilation theories posit that assimilation often entails access to more abundant socioeconomic resources, which could in turn benefit migrants' health (Alba \& Nee, 2003). On the other hand, there is an emerging awareness in recent scholarship that the process of assimilation may be stressful as it involves potential marginalization, discrimination and precarity as well as exposure to unhealthy lifestyles in socioeconomically deprived urban 
segments in host societies (Vang et al., 2017). Our results lend support to the latter arguments. Prior research tended to emphasize the benefits of urban hukou (Liang, 2016), but often overlooked the costs - including potential negative health consequences — associated with the lengthy and demanding process of obtaining an urban hukou. Therefore, our findings call upon scholars and policy-makers to take a more holistic view of assimilation and to move beyond the focus on the end of obtaining an urban hukou in mitigating socioeconomic and health inequalities. Rather, we urge scholars to consider the process of obtaining an urban hukou and its health implications.

Taken together, our findings show that rural-origin Chinese tend to experience health disadvantages regardless of whether they remain in rural areas, migrate temporarily or permanently to urban areas, or return to rural areas. Notably, the circular migration of rural Chinese to urban centers and, for some, back to rural areas represents a vicious "health grind" whereby healthy rural Chinese participate in the process of migration, contribute socioeconomically to the urban sectors in which they work (Liang, 2016), and are eliminated from the migratory cycle due partly to impaired health, without benefiting from the very urban economy and healthcare system to which they contribute. As the NRCMS fixates the healthcare of rural Chinese to their rural places of origin and that rural migrants are often hindered by staggering medical expenses to access urban healthcare (Liu et al., 2017), this vicious health cycle throughout China's internal migration may disproportionately over-burden the already under-resourced healthcare system in rural China (S. Wang, 2018). Therefore, our results call for particular attention to rural-to-urban migration and its health implications in the development of health policies in China in order to reduce health 
inequalities, improve overall population health, and optimize the allocation of health resources.

\section{Limitations and future research directions}

The limitations of this study suggest a few important directions for future research.

First, although the SF-12 is widely used to measure health outcomes, it is based on subjective self-report and may potentially be biased because rural and urban residents may adopt different referents for self-assessment and tend to have different levels of health awareness and expectations (Whyte \& Sun, 2010). Future analysis should also examine a broader range of objective health indicators. Moreover, due to data limitation this study only focuses on migration between rural and urban China. Future scholars could explore the health implications of diverse types of migration such as short-distance, intra-province, inter-province, rural-to-rural and urban-to-urban migration. Finally, our results from the PSM procedure are limited to an aggregate level, further efforts should be made to trace individuals throughout different migratory stages in order to uncover the causal relationship between migration and health at an individual level. Particularly, analysis of longitudinal panel data using fixed effects models could eliminate confounding effects arising from unobserved time-constant variables. Given the high prevalence of mobile phone usage among Chinese people and particularly migrants (van Velthoven et al., 2015), it would be beneficial to take advantage of mobile technologies to survey migrants more frequently than mainstream annual surveys. While our analytical framework offers a somewhat rigid understanding of China's internal migration, methodological innovations are required to provide more nuanced 
insights into individuals' fuzzy, non-linear migratory behaviors over time. 


\section{References}

Alba, R. D., \& Nee, V. (2003). Remaking the American Mainstream: Assimilation and Contemporary Immigration. Cambridge: Harvard University Press.

Chan, K. W. (2010). The household registration system and migrant labor in China: Notes on a debate. Population and Development Review, 36(2), 357-364.

https://doi.org/10.1111/j.1728-4457.2010.00333

Chen, J. (2011). Internal migration and health: Re-examining the healthy migrant phenomenon in China. Social Science and Medicine, 72(8), 1294-1301. https://doi.org/10.1016/j.socscimed.2011.02.016

Clark, W., \& Lisowski, W. (2017). Decisions to move and decisions to stay: Life course events and mobility outcomes. Housing Studies, 32(5), 547-565. https://doi.org/10.1080/02673037.2016.1210100

Coulter, R. (2013). Wishful thinking and the abandonment of moving desires over the life course. Environment and Planning A, 45(8), 1944-1962. https://doi.org/10.1068/a45314

Dai, J., Zhong, B.-L., Xiang, Y.-T., Chiu, H. F. K., Chan, S. S. M., Yu, X., \& Caine, E. D. (2015). Internal migration, mental health, and suicidal behaviors in young rural Chinese. Social Psychiatry and Psychiatric Epidemiology, 50(4), 621-631. https://doi.org/10.1007/s00127-014-0985-y

Guo, S., \& Fraser, M. W. (2010). Propensity Score Analysis : Statistical Methods and Applications. London: Sage .

Heckman, J. J., Ichimura, H., \& Todd, P. (1998). Matching as an econometric evaluation estimator. Review of Economic Studies, 65, 261-294. 
https://doi.org/0034-6527/98/00120261

Hesketh, T., Ye, X. J., Li, L., \& Wang, H. M. (2008). Health status and access to health care of migrant workers in China. Public Health Reports, 123(2), 189-197. https://doi.org/10.1177/003335490812300211

Hu, X., Cook, S., \& Salazar, M. A. (2008). Internal migration and health in China. The Lancet, 372(9651), 1717-1719. https://doi.org/10.1016/S0140-6736(08)61360-4

Hu, Y. (2016). Impact of rural-to-urban migration on family and gender values in China. Asian Population Studies, 12(3), 251-272. https://doi.org/10.1080/17441730.2016.1169753

Hu, Y., \& Coulter, R. (2017). Living space and psychological well-being in urban China: Differentiated relationships across socio-economic gradients. Environment and Planning A, 49(4), 911-929. https://doi.org/10.1177/0308518X16680213

Kley, S. (2011). Explaining the stages of migration within a life-course framework. European Sociological Review, 27(4), 469-486. https://doi.org/10.1093/esr/jcq020

Li, J., \& Rose, N. (2017). Urban social exclusion and mental health of China's rural-urban migrants - A review and call for research. Health \& Place, 48, 20-30. https://doi.org/10.1016/J.HEALTHPLACE.2017.08.009

Li, L., Wang, H., Ye, X., Jiang, M., Lou, Q., \& Hesketh, T. (2007). The mental health status of Chinese rural-urban migrant workers. Social Psychiatry and Psychiatric Epidemiology, 42(9), 716-722. https://doi.org/10.1007/s00127-007-0221-0

Li, X., Stanton, B., Fang, X., Xiong, Q., Yu, S., Lin, D., ... Wang, B. (2009). Mental health symptoms among rural-to-urban migrants in China: A comparison with their urban and 
rural counterparts. World Health \& Population, 11(1), 24-38.

Liang, Z. (2016). China's great migration and the prospects of a more integrated society. Annual Review of Sociology, 42(1), 451-471.

https://doi.org/10.1146/annurev-soc-081715-074435

Liu, G., Vortherms, S. A., \& Hong, X. (2017). China's health reform update. Annual Review of Public Health, 38(1), 431-448.

https://doi.org/10.1146/annurev-publhealth-031816-044247

Liu, Y., Zhang, F., Liu, Y., Li, Z., \& Wu, F. (2018). Economic disadvantages and migrants' subjective well-being in China: The mediating effects of relative deprivation and neighbourhood deprivation. Population, Space and Place, e2173. https://doi.org/10.1002/psp.2173

Lu, Y., \& Qin, L. (2014). Healthy migrant and salmon bias hypotheses: A study of health and internal migration in China. Social Science and Medicine, 102, 41-48. https://doi.org/10.1016/j.socscimed.2013.11.040

Mou, J., Cheng, J., Zhang, D., Jiang, H., Lin, L., \& Griffiths, S. M. (2009). Health care utilisation amongst Shenzhen migrant workers: Does being insured make a difference? BMC Health Services Research, 9(1), 214. https://doi.org/10.1186/1472-6963-9-214

Mou, J., Griffiths, S. M., Fong, H., \& Dawes, M. G. (2013). Health of China's rural-urban migrants and their families: A review of literature from 2000 to 2012. British Medical Bulletin, 106(1), 19-43. https://doi.org/10.1093/bmb/ldt016

Piotrowski, M., \& Tong, Y. (2013). Straddling two geographic regions: The impact of place of origin and destination on return migration intentions in China. Population, Space and 
Place, 19(3), 329-349. https://doi.org/10.1002/psp.1715

National Population and Family Planning Committee. (2017). 2017 Report on China's Migrant Population Development. Beijing: China Population Press.

Thomson, E. F., Nuru-Jeter, A., Richardson, D., Raza, F., \& Minkler, M. (2013). The Hispanic Paradox and older adults' disabilities: Is there a healthy migrant effect? International Journal of Environmental Research and Public Health, 10(5), 1786-1814. https://doi.org/10.3390/ijerph10051786

Tong, Y., \& Piotrowski, M. (2012). Migration and health selectivity in the context of Internal migration in China, 1997-2009. Population Research and Policy Review, 31(4), 497-543. https://doi.org/10.1007/s11113-012-9240-y

Vang, Z. M., Sigouin, J., Flenon, A., \& Gagnon, A. (2017). Are immigrants healthier than native-born Canadians? A systematic review of the healthy immigrant effect in Canada. Ethnicity and Health, 22(3), 209-241. https://doi.org/10.1080/13557858.2016.1246518

Wallace, M., \& Kulu, H. (2018). Can the salmon bias effect explain the migrant mortality advantage in England and Wales? Population, Space and Place, 24(8), e2146. https://doi.org/10.1002/psp.2146

Wang, L., \& Zhou, H. (2016). Health selectivity of migrant population: An analysis of CFPS 2010 and 2012 (China Family Panel Studies Working Paper Series: WP16-002). Beijing. Retrieved from http://www.isss.edu.cn/cfps/

Wang, S. (2018). Inching up and socio-economic differentiation: Exploring self-rated health of China's rural-to-urban migrants from 2005 to 2015. American Journal of Health Behavior, 42(5), 117-125. https://doi.org/10.5993/AJHB.42.5.10 
Wang, S., \& Mak, H.-W. (2018). Generational health improvement or decline? Exploring generational differences of British ethnic minorities in six physical health outcomes. Ethnicity \& Health. https://doi.org/10.1080/13557858.2018.1469736

Ware, J., Kosinski, M., \& Keller, S. (1998). How to Score the SF-12 Physical and Mental Health Summary Scales. Boston. Retrieved from https://www.researchgate.net/publication/242636950_SF-12_How_to_Score_the_SF-12 _Physical_and_Mental_Health_Summary_Scales

Whyte, M. K., \& Sun, Z. (2010). The impact of China's market reforms on the health of Chinese citizens: Examining two puzzles. China: An International Journal, 8(1), 1-32. https://doi.org/10.1142/S0219747210000038

Williams, A. M., Jephcote, C., Janta, H., \& Li, G. (2018). The migration intentions of young adults in Europe: A comparative, multilevel analysis. Population, Space and Place, 24(1), e2123. https://doi.org/10.1002/psp.2123

Xiao, W., \& Zhao, G. (2018). Agricultural land and rural-urban migration in China: A new pattern. Land Use Policy: The International Journal Covering All Aspects of Land Use, 74, 142-150. https://doi.org/10.1016/J.LANDUSEPOL.2017.05.013

Xie, S., Wang, J., Chen, J., \& Ritakallio, V.-M. (2017). The effect of health on urban-settlement intention of rural-urban migrants in China. Health \& Place, 47, 1-11. https://doi.org/10.1016/J.HEALTHPLACE.2017.06.008

Yang, X. (2014). Rural-urban migration and mental and sexual health: A case study in Southwestern China. Health Psychology and Behavioral Medicine, 2(1), 1-15. https://doi.org/10.1080/21642850.2013.839384 
Zhang, J., Li, A. X., Xiaoyi, A. E., Ae, F., \& Xiong, Q. (2009). Discrimination experience and quality of life among rural-to-urban migrants in China: The mediation effect of expectation-reality discrepancy. Quality of Life Research, 18(3), 291-300. https://doi.org/10.1007/s11136-009-9454-6

Zhang, L., Liu, S., Zhang, G., \& Wu, S. (2015). Internal migration and the health of the returned population: A nationally representative study of China. BMC Public Health, 15, 719. https://doi.org/10.1186/s12889-015-2074-x

Zhang, Z., \& Treiman, D. J. (2013). Social origins, hukou conversion, and the wellbeing of urban residents in contemporary China. Social Science Research, 42(1), 71-89. https://doi.org/10.1016/J.SSRESEARCH.2012.08.004 
Figure 1. Stages of rural-to-urban migration in China

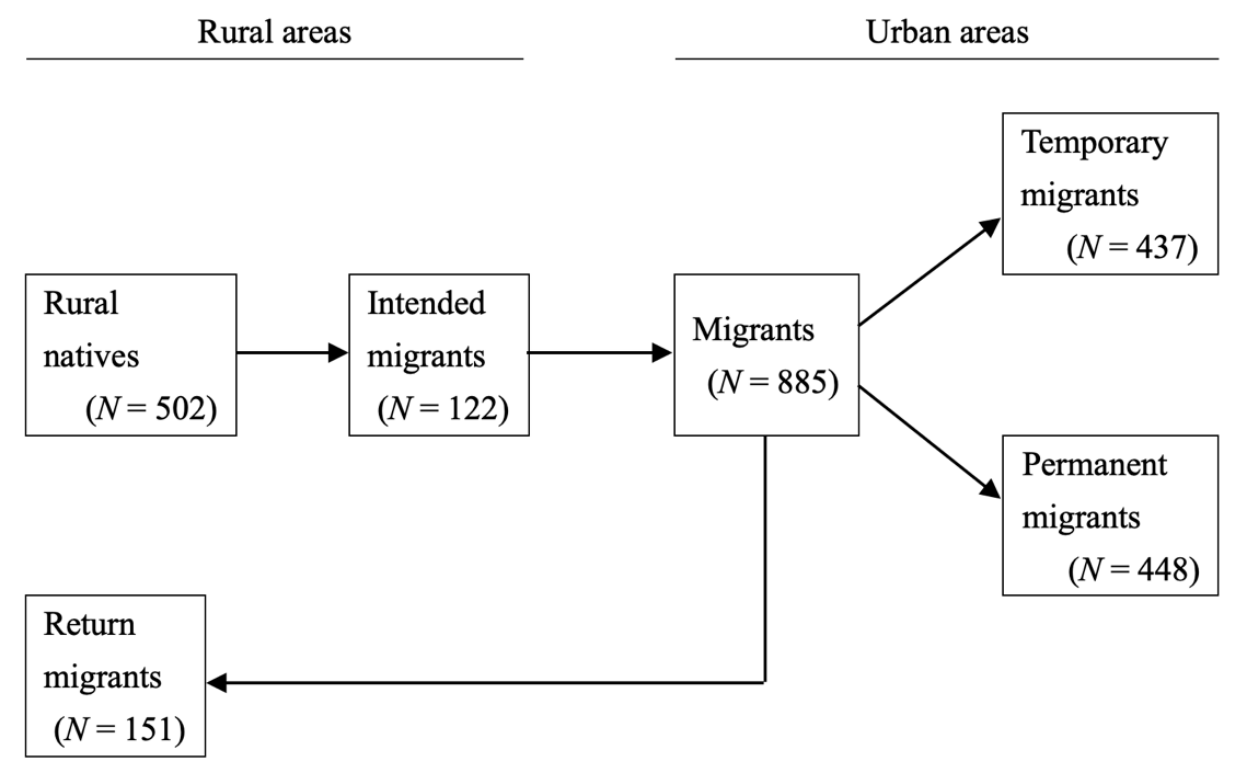

Note: Analytical sample sizes in this research in parentheses. 
Table 1. Sample characteristics

\begin{tabular}{|c|c|c|c|c|c|c|c|c|}
\hline Variables & $\begin{array}{l}\text { Rural } \\
\text { natives }\end{array}$ & $\begin{array}{l}\text { Return } \\
\text { migrants }\end{array}$ & $\begin{array}{l}\text { Intended } \\
\text { migrants }\end{array}$ & $\begin{array}{l}\text { Temporary } \\
\text { migrants }\end{array}$ & $\begin{array}{l}\text { Permanent } \\
\text { migrants }\end{array}$ & Min & Max & $\begin{array}{l}F / \chi^{2} \\
p \text {-value }\end{array}$ \\
\hline \multicolumn{9}{|l|}{ Dependent variables } \\
\hline SF-12: PCS & $\begin{array}{l}53.90 \\
(9.53)\end{array}$ & $\begin{array}{l}54.83 \\
(8.49)\end{array}$ & $\begin{array}{l}57.83 \\
(7.49)\end{array}$ & $\begin{array}{l}57.67 \\
(7.28)\end{array}$ & $\begin{array}{l}56.52 \\
(7.20)\end{array}$ & 17.13 & 64.12 & $<.001$ \\
\hline SF-12: MCS & $\begin{array}{l}42.73 \\
(10.52)\end{array}$ & $\begin{array}{l}43.12 \\
(10.27)\end{array}$ & $\begin{array}{l}46.12 \\
(10.27)\end{array}$ & $\begin{array}{l}45.46 \\
(9.35)\end{array}$ & $\begin{array}{l}45.10 \\
(10.94)\end{array}$ & 15.46 & 63.85 & $<.001$ \\
\hline \multicolumn{9}{|l|}{ Matching covariates } \\
\hline Age & $\begin{array}{l}43.90 \\
(8.62)\end{array}$ & $\begin{array}{l}40.83 \\
(8.77)\end{array}$ & $\begin{array}{l}36.03 \\
(8.77)\end{array}$ & $\begin{array}{l}36.67 \\
(8.93)\end{array}$ & $\begin{array}{l}39.52 \\
(9.34)\end{array}$ & 18 & 55 & $<.001$ \\
\hline Male & 39.36 & 56.95 & 63.11 & 42.99 & 46.43 & 0 & 1 & $<.01$ \\
\hline Has partner $(\mathrm{ref}=$ single $)$ & 93.57 & 88.74 & 81.97 & 80.92 & 83.04 & 0 & 1 & $<.001$ \\
\hline Children & & & & & & & & $<.001$ \\
\hline No child & 14.26 & 12.58 & 22.13 & 24.37 & 22.77 & 0 & 1 & \\
\hline Pre-school children $(0-5)$ & 10.24 & 16.56 & 14.75 & 15.63 & 14.29 & 0 & 1 & \\
\hline School age children (6-17) & 31.12 & 37.75 & 44.26 & 34.25 & 36.61 & 0 & 1 & \\
\hline Adult children $(18+)$ & 44.38 & 33.11 & 18.85 & 25.75 & 26.34 & 0 & 1 & \\
\hline $\begin{array}{l}\text { Average income in province of } \\
\text { residence (log) }\end{array}$ & $\begin{array}{c}9.36 \\
(0.14)\end{array}$ & $\begin{array}{c}9.37 \\
(0.17)\end{array}$ & $\begin{array}{c}9.41 \\
(0.19)\end{array}$ & $\begin{array}{c}9.48 \\
(0.26)\end{array}$ & $\begin{array}{c}9.51 \\
(0.27)\end{array}$ & 9.12 & 10.16 & .054 \\
\hline \multicolumn{9}{|l|}{ Matching mediators } \\
\hline Regular smoker & 29.32 & 39.07 & 45.90 & 28.51 & 28.35 & 0 & 1 & $<.001$ \\
\hline Regular alcohol consumer & 29.72 & 39.07 & 47.54 & 38.16 & 44.20 & 0 & 1 & $<.001$ \\
\hline Regular physical exercise & 19.08 & 29.14 & 30.33 & 45.75 & 64.73 & 0 & 1 & $<.001$ \\
\hline Education levels & & & & & & & & $<.001$ \\
\hline No education & 19.68 & 5.30 & 3.28 & 7.13 & 3.57 & 0 & 1 & \\
\hline Primary school & 38.76 & 29.14 & 28.69 & 22.07 & 8.26 & 0 & 1 & \\
\hline Middle school & 34.94 & 52.32 & 50.00 & 42.76 & 24.55 & 0 & 1 & \\
\hline High school & 5.42 & 3.97 & 12.30 & 14.48 & 15.18 & 0 & 1 & \\
\hline University/college and above & 1.20 & 9.27 & 5.74 & 13.56 & 48.44 & 0 & 1 & \\
\hline EGP occupational status & & & & & & & & $<.001$ \\
\hline No work & 79.92 & 5.96 & 34.43 & 24.37 & 10.94 & 0 & 1 & \\
\hline Higher controller & 6.02 & 18.54 & 12.30 & 22.07 & 38.39 & 0 & 1 & \\
\hline Routine non-manual & 1.20 & 3.97 & 4.10 & 12.41 & 18.75 & 0 & 1 & \\
\hline Manual & 9.84 & 62.25 & 43.44 & 33.10 & 25.89 & 0 & 1 & \\
\hline Farm-related and other work & 3.01 & 9.27 & 5.74 & 8.05 & 6.03 & 0 & 1 & \\
\hline$N$ & 502 & 151 & 122 & 437 & 448 & 0 & 1 & \\
\hline
\end{tabular}

Note: SF-12 = 12-Item Short Form Health Survey. PCS = Physical Component Summary. MCS = Mental Component Summary. Proportions reported for categorical variables. Mean values reported for continuous variables. Standard deviations in parenthesis. Two-tailed $F$ and $\chi^{2}$ tests were conducted for inter-group comparisons. Column percentages may not add up to 1 due to rounding. Dummy variables indicated by a minimum value of 0 and a maximum value of 1 . 
Table 2. Balancing properties of the matched sample

\begin{tabular}{llllc}
\hline Treatment & Control & $\begin{array}{l}\text { Bias statistic before } \\
\text { matching }\left(\chi^{2}, p \text {-value }\right)\end{array}$ & $\begin{array}{l}\text { Bias statistic after } \\
\text { matching }\left(\chi^{2}, p \text {-value }\right)\end{array}$ & Bias reduction \% \\
\hline Intended migrants & Rural natives & $40.8(96.5, p=.000)$ & $9.2(4.1, p=.772)$ & 77.5 \\
Return migrants & Migrants & $22.5(59.6, p=.000)$ & $10.2(6.2, p=.518)$ & 54.7 \\
Migrants & Intended migrants & $17.6(35.3, p=.000)$ & $5.0(7.4, p=.387)$ & 71.6 \\
Temporary migrants & Intended migrants & $17.7(30.3, p=.000)$ & $4.2(3.1, p=.879)$ & 76.3 \\
Permanent migrants & Intended migrants & $19.2(36.6, p=.000)$ & $7.0(10.5, p=.164)$ & 63.5 \\
Permanent migrants & Temporary migrants & $7.8(19.9, p=.006)$ & $4.4(3.1, p=.877)$ & 43.6 \\
\hline
\end{tabular}

Note: Balancing check tests were conducted after PSM using the $p$ stest function in the Stata package psmatch2. 
Table 3. Propensity score matching with regression adjustments (RA) estimating the average treatment effects on the treated (ATT), with 95\% confidence intervals: "Healthy migrant" hypothesis and "salmon" hypotheses

\begin{tabular}{|c|c|c|c|c|}
\hline & Raw differences & Matched ATT & RA. (SES) ATT & RA. (SES + HB) ATT \\
\hline Panel A & \multicolumn{4}{|c|}{ Rural natives (control) vs. Intended migrants (treated) } \\
\hline \multirow[t]{2}{*}{ Physical health (PCS) } & $4.37 * * *$ & $1.49 \dagger$ & 1.07 & 0.59 \\
\hline & $(2.55,6.18)$ & $(-0.24,3.23)$ & $(-1.25,3.39)$ & $(-1.74,2.92)$ \\
\hline \multirow[t]{2}{*}{ Mental health (MCS) } & $3.87 * * *$ & 1.36 & -.54 & -0.20 \\
\hline & $(1.83,5.91)$ & $(-0.98,-3.70)$ & $(-3.45,-2.36)$ & $(-3.15,-2.74)$ \\
\hline$N$ (control) & 502 & 502 & 502 & 502 \\
\hline$N($ treated $)$ & 122 & 115 & 115 & 115 \\
\hline Panel B & \multicolumn{4}{|c|}{ Temporary/permanent migrants (control) vs. Return migrants (treated) } \\
\hline \multirow[t]{2}{*}{ Physical health (PCS) } & $-2.08 * *$ & $-1.07^{*}$ & -0.79 & -0.63 \\
\hline & $(-3.47,-0.70)$ & $(-3.18,-0.22)$ & $(-2.77,-1.18)$ & $(-2.64,-1.37)$ \\
\hline \multirow[t]{2}{*}{ Mental health (MCS) } & $-1.68 \dagger$ & $-1.76^{\dagger}$ & -0.75 & -1.21 \\
\hline & $(-3.42,-0.05)$ & $(-3.56,-0.03)$ & $(-3.24,1.74)$ & $(-3.72,-1.29)$ \\
\hline$N$ (control) & 151 & 150 & 150 & 150 \\
\hline$N$ (treated) & 885 & 885 & 885 & 885 \\
\hline
\end{tabular}

Note $:$ PCS $=$ Physical Component Summary. MCS $=$ Mental Component Summary. SES $=$ Socioeconomic status. HB $=$ Health behaviors. Local linear regression matching with replacements and ties. 95\% confidence intervals in parenthesis, calculated using 200 bootstrap simulations to account for the uncertainly involved in the estimation of propensity scores.

$\dagger p<.10, * p<.05, * * p<.01, * * * p<.001$. 
Table 4. Propensity score matching with regression adjustments (RA) estimating the average treatment effects on the treated (ATT), with 95\% confidence intervals: The health impact of migration, by hukou status

\begin{tabular}{|c|c|c|c|c|}
\hline & Raw difference & Matched ATT & RA. (SES) ATT & RA. (SES + HB) ATT \\
\hline Panel A & \multicolumn{4}{|c|}{ Intended migrants (control) vs. Temporary/permanent migrants (treated) } \\
\hline Physical health (PCS) & $\begin{array}{l}-0.65 \\
(-2.15,0.83)\end{array}$ & $\begin{array}{l}-0.79 \\
(-2.46,0.87)\end{array}$ & $\begin{array}{l}-1.72 * * * \\
(-2.67,-0.76)\end{array}$ & $\begin{array}{l}-1.75 * * * \\
(-2.71,-0.79)\end{array}$ \\
\hline Mental health (MCS) & $\begin{array}{l}-1.55 \\
(-3.47,0.36)\end{array}$ & $\begin{array}{l}-1.93 \dagger \\
(-4.03,0.15)\end{array}$ & $\begin{array}{l}-2.95 * * * \\
(-4.35,-1.56)\end{array}$ & $\begin{array}{l}-2.97 * * * \\
(-4.37,-1.58)\end{array}$ \\
\hline$N$ (control) & 122 & 122 & 122 & 122 \\
\hline$N($ treated $)$ & 885 & 868 & 868 & 868 \\
\hline Panel B & \multicolumn{4}{|c|}{ Intended migrants (control) vs. Temporary migrants (treated) } \\
\hline \multirow[t]{2}{*}{ Physical health (PCS) } & -0.37 & -0.57 & 0.25 & 0.31 \\
\hline & $(-1.94,1.18)$ & $(-2.10,0.96)$ & $(-0.99,1.49)$ & $(-0.94,1.57)$ \\
\hline \multirow[t]{2}{*}{ Mental health (MCS) } & -1.67 & -1.79 & -0.68 & -0.73 \\
\hline & $(-3.66,0.31)$ & $(-4.01,0.41)$ & $(-2.48,1.11)$ & $(-2.54,1.08)$ \\
\hline$N$ (control) & 122 & 122 & 122 & 122 \\
\hline$N($ treated $)$ & 437 & 418 & 418 & 418 \\
\hline Panel C & \multicolumn{4}{|c|}{ Intended migrants (control) vs. Permanent migrants (treated) } \\
\hline \multirow[t]{2}{*}{ Physical health (PCS) } & -0.92 & -0.63 & $-2.73 * *$ & $-2.57 * *$ \\
\hline & $(-2.51,0.65)$ & $(-2.17,0.90)$ & $(-4.35,-1.11)$ & $(-4.20,-0.93)$ \\
\hline \multirow[t]{2}{*}{ Mental health (MCS) } & -1.44 & $-1.84 \dagger$ & $-4.13 * * *$ & $-3.96 * * *$ \\
\hline & $(-3.53,0.64)$ & $(-4.03,0.34)$ & $(-6.33,-1.93)$ & $(-6.15,-1.77)$ \\
\hline$N$ (control) & 122 & 122 & 122 & 122 \\
\hline$N$ (treated) & 448 & 432 & 432 & 432 \\
\hline Panel D & \multicolumn{4}{|c|}{ Temporary migrants (control) vs. Permanent migrants (treated) } \\
\hline \multirow[t]{2}{*}{ Physical health (PCS) } & -0.55 & -0.15 & $-2.63 * * *$ & $-2.48 * * *$ \\
\hline & $(-1.59,0.49)$ & $(-1.11,0.81)$ & $(-3.90,-1.53)$ & $(-3.76,-1.21)$ \\
\hline \multirow[t]{2}{*}{ Mental health (MCS) } & .23 & .18 & $-1.86 \dagger$ & $-1.59 \dagger$ \\
\hline & $(-1.10,1.56)$ & $(-1.18,1.56)$ & $(-3.60,-0.13)$ & $(-3.32,0.13)$ \\
\hline$N$ (control) & 437 & 437 & 437 & 437 \\
\hline$N$ (treated) & 448 & 448 & 448 & 448 \\
\hline
\end{tabular}

Note: PCS $=$ Physical Component Summary. MCS $=$ Mental Component Summary. SES $=$ Socioeconomic status. HB $=$ Health behaviors. Local linear regression matching with replacements and ties. $95 \%$ confidence intervals in parenthesis, calculated using 200 simulations to account for the uncertainly involved in the estimation of propensity scores.

$\dagger p<.10, * p<.05, * * p<.01, * * * p<.001$. 